\title{
Nutritional intervention programme among a Japanese-Brazilian community: procedures and results according to gender
}

\author{
Renata Damião ${ }^{1}$, Daniela Saes Sartorelli ${ }^{2}$, Amélia Hirai $^{3}$, Flávia Massimino ${ }^{3}$, Juliana \\ Poletto $^{3}$, Marselle Rodrigues Bevilacqua ${ }^{3}$, Rita Chaim ${ }^{4}$, Vera Lúcia Morais Antonio de \\ Salvo $^{3}$, Leiko Asakura ${ }^{3}$, Sandra Roberta Gouveia Ferreira ${ }^{5}$, Solange Andreoni ${ }^{3}$ and \\ Suely Godoy Agostinho Gimeno ${ }^{3, *}$ for the Japanese-Brazilians Diabetes Study Groupt \\ ${ }^{1}$ Nutrition Graduation Course, Triângulo Mineiro Federal University, Uberaba, Minas Gerais, Brazil: ${ }^{2}$ Social \\ Medicine Department, Ribeirão Preto Medicine Faculty, University of São Paulo, Ribeirão Preto, São Paulo, \\ Brazil: ${ }^{3}$ Preventive Medicine Department, São Paulo Federal University, Rua Borges Lagoa 1341, Vila \\ Clementino, São Paulo, São Paulo, CEP 040038-034, Brazil: ${ }^{4}$ Nutrition Department, Sagrado Coração \\ University, Bauru, São Paulo, Brazil: ${ }^{5}$ Nutrition Department, Public Health Faculty, University of São Paulo, \\ São Paulo, Brazil
}

Submitted 13 September 2009: Accepted 12 March 2010: First published online 5 May 2010

\begin{abstract}
Objective: To describe the results of a nutritional intervention programme among Japanese-Brazilians according to gender.

Design: A non-controlled experimental study.

Setting: The research included three points of clinical, nutritional and physical activity evaluation: at baseline (in 2005), after the first year and at the end of the second year (in 2007). The paired Student $t$ test and multiple linear regression analysis were used to evaluate changes in the subjects' profile (clinical, nutritional and physical activity variables).

Subjects: Japanese-Brazilians ( $n$ 575) of both genders, aged over 30 years.

Results: We verified statistically significant reductions in body weight $(0.9 \mathrm{~kg})$, waist circumference $(2.9 \mathrm{~cm})$, blood pressure, fasting blood glucose $(>3 \mathrm{mg} / \mathrm{dl})$ and total cholesterol $(>20 \mathrm{mg} / \mathrm{dl})$ and its fractions, in both genders. We also found reductions in intake of energy (among men), protein (among women) and fat (both genders) and increases in intake of total fibre (among women) and carbohydrate (among men).

Conclusions: The intervention programme indicated meaningful benefits for the intervention subjects, with changes in their habits that led to a 'healthier' lifestyle positively impacting their nutritional and metabolic profile.
\end{abstract}

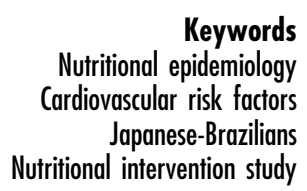

Nutritional epidemiology ovascular risk factors Nutritional intervention study
Globally, CVD are the main cause of morbidity and mortality. They present multiple factors and several common mechanisms, and are highly influenced by inflammatory activity. Among the common and modifiable risk factors associated with CVD are diabetes mellitus (DM), hypertension, dyslipdaemia, hypertriacylglycerolaemia and obesity. Addressing the risk factors decreases the incidence and development of these diseases ${ }^{(1,2)}$.

It is known that Japanese people who live in Japan present lower CVD morbidity and mortality rates than Japanese immigrants and their descendents who live in the Americas ${ }^{(3)}$. Brazil is home to the largest Japanese

$\dagger$ See Appendix for list of members of the Japanese-Brazilian Diabetes Study Group. population outside Japan (around 1280000 people) and more than $70 \%$ of this total lives in the south-east region, mainly in the State of São Paulo ${ }^{(4)}$. The size of this community, along with the results of American studies about the prevalence of type 2 DM among Japanese descendents in the USA ${ }^{(5)}$, led to the creation of the JapaneseBrazilian Diabetes Study Group (JBDSG). The results of studies of this group of researchers, carried out according to WHO guidelines ${ }^{(6)}$, have shown that the prevalence of type $2 \mathrm{DM}$ was $25.5 \%$ for men and $19 \cdot 9 \%$ for women in 1993 , increasing to $40.6 \%$ and $32 \cdot 4 \%$, respectively, in $2000^{(7)}$. Significant increases in BMI and in all other risk factors of the metabolic syndrome have also been noticed $^{(8)}$. These findings indicate the existence of a strong genetic predisposition associated with unfavourable 


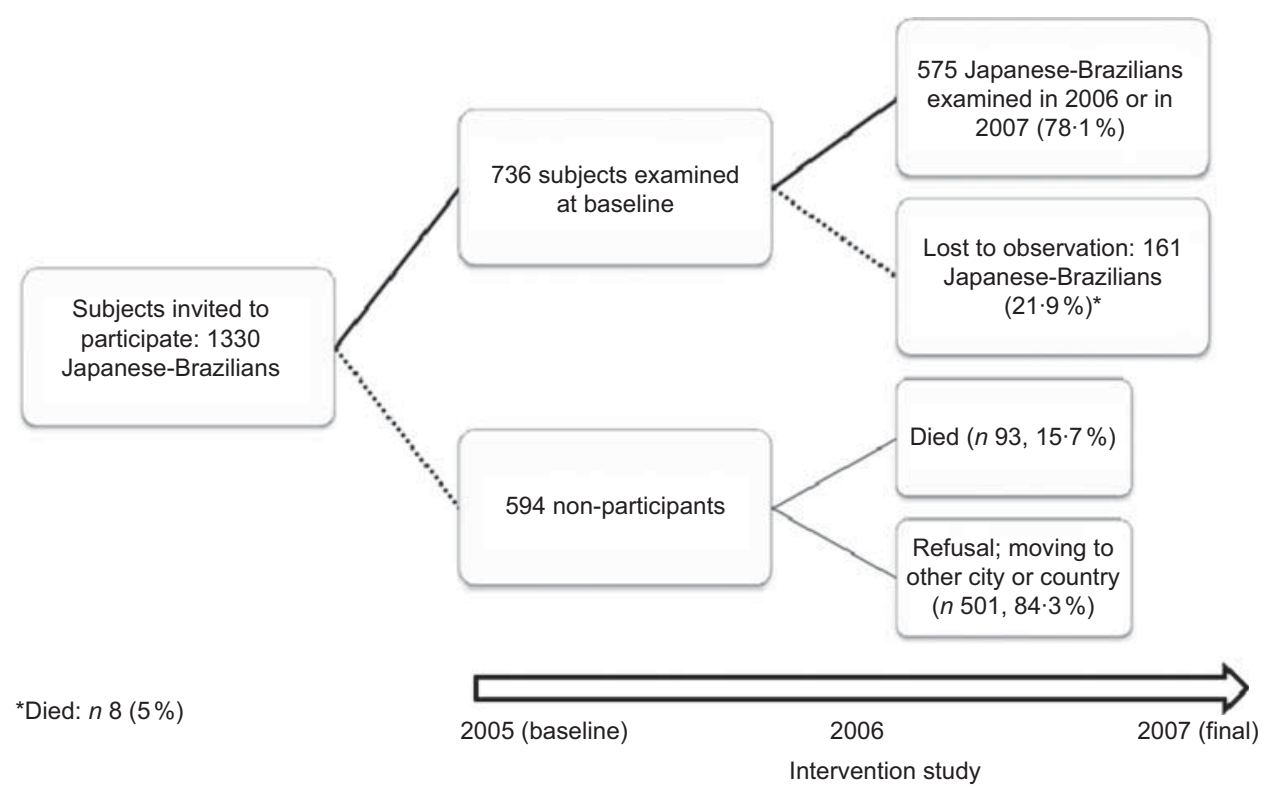

Fig. 1 Participants in the nutritional intervention study, Baura, São Paulo, Brazil, 2007

environmental conditions related to the occidental lifestyle, and the need to implement measures to prevent and control the problem among these immigrants.

Epidemiological studies reporting the efficiency of lifestyle changes in decreasing the incidence of type $2 \mathrm{DM}$ can be found in the literature ${ }^{(9,10)}$. The results of surveys conducted with individuals presenting impaired glucose tolerance and excess weight have shown that changes in lifestyle are more effective than drug-based interventions ${ }^{(11)}$. However, as pointed by Sarrafzadegan et al. ${ }^{(12)}$, these evidences are less clear for developing countries and intervention studies in such countries have been scarce.

In this context, the main objective of the present study was to describe the results of a nutritional intervention programme carried out with Japanese-Brazilians according to gender.

\section{Experimental methods}

This was a non-controlled experimental study that was developed according to principles embodied in the Declaration of Helsinki. It was approved by the Research Ethics Committee of São Paulo Federal University UNIFESP (protocol number 0862/05).

Considering the unfavourable cardiovascular profile found among Japanese-Brazilians as previously described by JBDSG researchers ${ }^{(7,8)}$, characterized by a high percentage of glucose intolerance (70\%), hypertension (58\%), dyslipidaemia (65\%) and central obesity (57\%), all participants of the JBDSG study conducted in 2000 ( $n$ 1330) were invited to participate in the current nutritional intervention programme regardless of their chronic diseases or nutritional status. They represented the total
Japanese-Brazilian first (Japan born) and second (born in Brazil) generation living in Bauru (State of São Paulo, south-east region of Brazil) of both genders and $\geq 30$ years of age. In total 736 Japanese-Brazilians joined the intervention programme. Reasons for non-attendance $(44 \cdot 7 \%)$ were death $(15 \cdot 7 \%)$, moving to other city or country and refusal $(84 \cdot 3 \%)$. Unimportant differences were observed concerning gender, age, generation and glucose tolerance status between non-participants and participants of the intervention study. The data of 575 subjects $(78 \cdot 1 \%)$ who had been evaluated at least twice, at baseline (2005) and final (2006 or 2007), were used in the present analysis (Fig. 1).

The nutritional intervention programme was communicated through letters and community events. All subjects were informed about the research objectives, of the minimum risks associated with blood collection with disposable materials and of the advantages of participating in the nutritional programme; information reliability and confidentiality were secured. Those who agreed to participate signed an informed consent agreement.

The survey included three clinical examinations: at baseline (2005), after the first intervention year (2006) and at the end of the second year (2007). On these occasions, subjects were physically examined, fasting blood samples were collected for several biochemical analyses and three $24 \mathrm{~h}$ dietary recalls were completed.

\section{Nutritional intervention strategy}

The nutritional intervention was based on a programme previously conducted at a health-care service of the State of São Paulo ${ }^{(13,14)}$. Improvements in the anthropometric (primary outcome), clinical and biochemical profiles of the Japanese-Brazilian subjects were the goals of the 
intervention programme. Individual energy requirements and nutritional status of each subject were taken into consideration for diet prescription. For those presenting overweight or central obesity, a diet with reduced energy (2092 to $4184 \mathrm{~kJ} / \mathrm{d}$ ) was prescribed, aiming at a $5 \%$ weight loss. Diet consisted of five meals per day with the following distribution of total energy: 50-60\% from carbohydrates (mainly complex carbohydrates); less than $10 \%$ from SFA (red meat intake reduced to two medium servings daily, two or three daily servings of low-fat dairy products, and reduced intake of fried food, fat, mayonnaise, industrialized food dressing, fatty meat, poultry skin and too many eggs); minimum of $20 \%$ from MUFA and PUFA (olive oil, nuts and fish); and $400 \mathrm{~g}$ of fruits and vegetables daily (equivalent to five servings).

The intervention plan was divided into two phases: (i) an individual nutritional assessment and (ii) two group orientation meetings (at the first and second year of the intervention programme) coordinated by nutritionists. In the first phase subjects received an individual assessment: their food records were checked, a detailed nutritional evaluation was made (food intake, energy needs, nutritional status, clinical and biochemical examinations), a diet was prescribed with a list of food replacements, and orientation was given on the importance of a healthy diet and physical activity. The two group meetings focused on food intake goals, physical activity, healthy lifestyle and discussion about difficulties faced by the subjects. Physical therapists and nutritionists supported these sessions.

\section{Evaluation measures}

In the three clinical examinations, all subjects were invited to come fasting ( $10 \mathrm{~h}$ minimum) to the clinical laboratory of Sagrado Coração University (Bauru), where a physical examination and a biochemical evaluation were done by the medical staff of UNIFESP. The physical examination included anthropometric measurements and evaluation of blood pressure and physical activity. For those who were not fluent in the Portuguese language, family members or bilingual staff members helped perform the examinations.

After collection of baseline data, results were informed to the participants and those who had health problems were sent for medical care; at that time, appointments with nutritionists were scheduled (subjects and their family members) for orientation on healthy lifestyle.

At the three clinical examinations (baseline in 2005; intermediate in 2006; final in 2007) three $24 \mathrm{~h}$ recalls were obtained by nutritionists during the group meetings, laboratory examinations or clinical examinations. Detailed information on food and beverages consumed in the last $24 \mathrm{~h}$ was requested. All questionnaires were revised in order to check data quality. Data of food intake in household measures were transformed into grams. To avoid discrepancies when typing data, all recipes and preparations were standardized according to a previously elaborated codification manual. NutWin software (Programa de Apoio à Nutrição, Versão 1.5; Escola Paulista de Medicina, São Paulo, Brazil) was used to quantity nutrient intake. National and international food composition tables were used for those foods not included in the above software ${ }^{(15-17)}$. In all clinical examinations, the average values of the nutrients gathered in the three $24 \mathrm{~h}$ dietary recalls were analysed to evaluate possible changes in dietary habits.

During the clinical assessment, weight $(\mathrm{kg})$ and height (m) were measured using a digital scale $(150 \mathrm{~kg}$ capacity, $100 \mathrm{~g}$ precision) and a portable stadiometer, respectively. Waist circumference $(\mathrm{cm})$ was measured with a measuring tape at navel level, with subjects standing upright, with relaxed abdomen, arms along the body and feet together. Blood pressure measurements were taken three times with an automatic monitor (model HEM-712C; Omron Healthcare, Inc., Bannockburn, IL, USA) approved by the American Heart Association for epidemiological studies. After a rest for $5 \mathrm{~min}$, the cuff was applied to the right upper arm of the subject who was seated, and automatically inflated. Deflation occurred at a speed predetermined by the equipment. Final values of systolic and diastolic blood pressure were the arithmetic average of the last two measurements ( $\mathrm{mmHg}$ ). Also, the physical activity of the Japanese-Brazilians was evaluated using the short version of the International Physical Activity Questionnaire (IPAQ), which has been validated in twelve countries including Brazil ${ }^{(18,19)}$. A fasting blood sample was collected to determine glucose level and lipid profile (total cholesterol and its fractions, TAG), among others. The glucose oxidation method was used to determine glycaemia and enzymatic kits were used to measure lipoproteins.

\section{Statistical analyses}

Data from the laboratory and anthropometric examinations were analysed with the STATA statistical software package version 10.0 (Stata Corp., College Station, TX, USA). Relative and absolute frequencies, measures of central tendency and dispersion of clinical, biochemical, dietary and anthropometric variables, collected at different time points, were calculated. In crude analyses the paired Student $t$ test was used to verify the presence of statistically significant alterations in nutritional, clinical and biochemical indices at the end of the intervention programme. Absolute changes in all variables of interest (final minus baseline value) observed during the intervention programme were compared between men and women who achieved the study goal (improvement in anthropometric profile) or not, using the Student $t$ test. Multiple linear regression analysis was employed to adjust the absolute change in all variables according to their baseline values and number of examinations (two or three). For analysis purposes, all nutrients were adjusted by energy according to Willett and Stampfer ${ }^{(20)}$. 


\section{Results}

The 161 (21.9\%) Japanese-Brazilians excluded from the present analysis (those who had been examined just once) presented similar frequency distributions to those who were evaluated two or three times for gender, age, BMI and waist circumference $(P>0 \cdot 05)$.

Of the 575 subjects who participated in the nutritional intervention programme, 197 were evaluated twice (baseline and final: at 12 or 24 months), while 378 were examined three times (baseline, intermediate and final). Analysis of frequency distributions according to sociodemographic characteristics, anthropometric measures, health status and examinations performed showed a statistically higher rate of individuals with central obesity or normal glucose tolerance among those with two evaluations, compared with those who were evaluated three times.

Female and second-generation subjects represented $56.9 \%$ and $84.7 \%$ of the participants in the intervention programme, respectively. Table 1 shows mean values of anthropometric, clinical, biochemical, dietary and physical activity variables for Japanese-Brazilian men. Comparison of baseline and final values (crude and adjusted changes) showed significant reductions of body weight, waist circumference, blood pressure, fasting glucose, TAG, total cholesterol and its fractions, and energy, SFA and fibre intakes. During this period a statistically significant increase of carbohydrate intake was also observed.

The comparison of values of baseline and final variables among women showed statistically significant decreases in weight, waist circumference, blood pressure, fasting glucose, total cholesterol and its fractions, and protein, total fat (including PUFA, MUFA and SFA) and fibre intakes (Table 2). The mean daily intake of carbohydrate and alcohol increased during the study period.

Both genders showed a significant mean weight loss $(0.9 \mathrm{~kg})$ and a reduction in waist circumference $(2.9 \mathrm{~cm})$. Among all subjects, $32 \cdot 5 \%$ ( $n$ 172) achieved the primary goal of the study. Table 3 shows the main features of these Japanese-Brazilians according to gender. Statistically significant improvements in nutritional and metabolic profile were observed among those who achieved the study goals, especially in men (weight, BMI and TAG levels). Even among those who did not achieve the study goal, some benefits to cardiovascular health were apparently reported, particularly in men.

\section{Discussion}

The present intervention was based on a programme previously applied among overweight Brazilian subjects at a primary health-care centre that was effective in a short follow-up time ${ }^{(13,14)}$. In the present study, we verified that this programme is also suitable for free-living Japanese-Brazilian subjects after 24 months of follow-up.
Nutritional intervention studies among Japanese migrants are sparse in the literature.

In both genders, a substantial improvement in nutritional and metabolic profile was detected during the study. Comparison of the results of both genders suggests that men have achieved better results, with important changes in their anthropometric and metabolic profiles (except HDL cholesterol levels), even with no significant changes in physical activity and food intake. It is important to note that a decrease in energy intake due to reduced SFA intake can contribute to decrease LDL cholesterol levels, as observed in the present study. Although diet compliance has not been evaluated, the results presented suggest (indirectly) that it was, at least, moderate.

Several studies have shown the efficacy of lifestyle intervention programmes in reducing the incidence of type $2 \mathrm{DM}$, reporting body weight reduction, better glucose tolerance, decreased blood pressure and improved plasma lipid profile of the subjects. In their study with 1232 normotense and hypercholesterolaemic subjects aged between 40 and 49 years, Forti and Diament observed that after a 5 -year oriented diet the intervention group presented a $45 \%$ reduction of myocardial infarction risk because of decreased hypercholesterolaemia (13\%) and TAG levels (20\%) and increased HDL cholesterol levels $(20 \%)^{(21)}$. Researchers of the Multiple Risk Factor Intervention Trial (MRFIT) followed up 12866 high-risk subjects from twenty-two US clinical centres. The subjects were divided into two groups: (i) the intervention group (participants received group and individual counselling on smoking cessation, drug treatment programme and hypocholesterolaemic diet) and (ii) the usual care group (subjects were informed about risk factor reduction and drug treatment programme). After 6 years of follow-up, subjects from the intervention group presented a decline in hypercholesterolaemia (5\%) and smoking habit (50\%). Over a longer period of time $(10.5$ years) subjects in the intervention group showed a $36 \%$ reduction of CHD mortality risk compared with those in the usual care group ${ }^{(22)}$.

In weight-loss studies a lack of accuracy in selfreporting of food consumption and physical activities is frequently reported ${ }^{(23)}$. In this regard, in our study dietary intake was assessed every meeting using standardized procedures by highly trained nutritionists; however, the limitations of the $24 \mathrm{~h}$ dietary recall, such as underreporting mainly by women and by those with higher body weight, are well described ${ }^{(24)}$.

In our study $21.9 \%$ of the subjects evaluated at baseline were lost to observation; this is a problem frequently found in epidemiological studies with moderate- to longterm follow-up ${ }^{(25-28)}$. Considering that the subjects lost presented similar frequency distribution to those who were evaluated two or three times according to some characteristics of interest (gender, age, BMI, waist circumference), we can conclude that the study population 
Table 1 Baseline and final mean values with standard deviations, and absolute change and adjusted change with $95 \%$ confidence intervals, of anthropometric, clinical, biochemical, dietary and physical activity variables of Japanese-Brazilian men during the intervention programme, Bauru, São Paulo, Brazil, 2007

\begin{tabular}{|c|c|c|c|c|c|c|c|c|c|c|}
\hline \multirow[b]{2}{*}{ Variable } & \multirow[b]{2}{*}{$n$} & \multicolumn{2}{|c|}{ Baseline } & \multicolumn{2}{|c|}{ Final } & \multirow[b]{2}{*}{$P$ value* } & \multirow[b]{2}{*}{ Absolute changet } & \multirow[b]{2}{*}{$95 \% \mathrm{Cl}$} & \multirow[b]{2}{*}{ Adjusted changeł } & \multirow[b]{2}{*}{$95 \% \mathrm{Cl}$} \\
\hline & & Mean & SD & Mean & SD & & & & & \\
\hline Weight (kg) & 232 & $68 \cdot 2$ & $12 \cdot 1$ & $67 \cdot 3$ & $12 \cdot 4$ & $<0.001$ & -0.93 & $-1 \cdot 28,-0.58$ & -0.93 & $-1 \cdot 27,-0.58$ \\
\hline BMI $\left(\mathrm{kg} / \mathrm{m}^{2}\right)$ & 213 & $25 \cdot 2$ & $4 \cdot 0$ & $25 \cdot 2$ & $4 \cdot 2$ & $0 \cdot 350$ & 0.03 & $-0 \cdot 12,0 \cdot 18$ & 0.03 & $-0 \cdot 13,0 \cdot 18$ \\
\hline WC $(\mathrm{cm})$ & 232 & $91 \cdot 6$ & $9 \cdot 6$ & $89 \cdot 6$ & $10 \cdot 9$ & 0.001 & -1.99 & $-2.99,-0.98$ & $-2 \cdot 03$ & $-3 \cdot 01,-1 \cdot 05$ \\
\hline $\mathrm{DBP}(\mathrm{mmHg})$ & 233 & $83 \cdot 1$ & $11 \cdot 2$ & $78 \cdot 7$ & $11 \cdot 8$ & $<0.001$ & $-4 \cdot 42$ & $-5 \cdot 71,-3 \cdot 13$ & $-4 \cdot 46$ & $-5 \cdot 65,-3 \cdot 27$ \\
\hline SBP $(\mathrm{mmHg})$ & 233 & $140 \cdot 6$ & $19 \cdot 6$ & $133 \cdot 5$ & $19 \cdot 3$ & $<0.001$ & $-7 \cdot 14$ & $-9 \cdot 32,-4 \cdot 96$ & $-7 \cdot 28$ & $-9 \cdot 23,-5 \cdot 32$ \\
\hline Fasting glucose (mg/dl) & 248 & $116 \cdot 3$ & $31 \cdot 4$ & $109 \cdot 1$ & 26.9 & $<0.001$ & $-7 \cdot 21$ & $-10 \cdot 20,-4 \cdot 22$ & $-7 \cdot 21$ & $-9 \cdot 71,-4 \cdot 72$ \\
\hline $\mathrm{TC}(\mathrm{mg} / \mathrm{dl})$ & 248 & $207 \cdot 8$ & $45 \cdot 2$ & $186 \cdot 8$ & $38 \cdot 3$ & $<0.001$ & $-20 \cdot 93$ & $-25 \cdot 71,-16 \cdot 14$ & $-20 \cdot 93$ & $-24 \cdot 80,-17 \cdot 06$ \\
\hline HDL-C (mg/dl) & 247 & $49 \cdot 0$ & $12 \cdot 2$ & $46 \cdot 1$ & $10 \cdot 9$ & $<0.001$ & $-2 \cdot 87$ & $-4 \cdot 22,-1 \cdot 53$ & $-2 \cdot 87$ & $-3 \cdot 99,-1 \cdot 76$ \\
\hline LDL-C (mg/dl) & 223 & $123 \cdot 2$ & $37 \cdot 4$ & $107 \cdot 3$ & $33 \cdot 6$ & $<0.001$ & $-14 \cdot 88$ & $-19 \cdot 44,-10 \cdot 32$ & $-14 \cdot 89$ & $-18 \cdot 60,-11 \cdot 17$ \\
\hline TAG $(\mathrm{mg} / \mathrm{dl}) \S$ & 246 & $193 \cdot 6$ & $207 \cdot 9$ & $169 \cdot 5$ & $114 \cdot 6$ & 0.030 & $-24 \cdot 13$ & $-49 \cdot 19,0 \cdot 92$ & $-24 \cdot 14$ & $-37 \cdot 66,-10 \cdot 61$ \\
\hline Energy $(\mathrm{kJ} / \mathrm{d})$ & 235 & $9737 \cdot 8$ & $3414 \cdot 1$ & $9146 \cdot 6$ & $3173 \cdot 6$ & 0.003 & $-591 \cdot 40$ & $-1004 \cdot 04,-178 \cdot 36$ & $-592 \cdot 71$ & $-939 \cdot 98,-244 \cdot 76$ \\
\hline Carbohydrate $(g / d) \|$ & 235 & $300 \cdot 0$ & $105 \cdot 3$ & $288 \cdot 1$ & $100 \cdot 4$ & $<0.001$ & 0.11 & $0.07,0.15$ & $0 \cdot 11$ & $0.07,0.14$ \\
\hline Protein $(g / d) \|$ & 235 & $102 \cdot 6$ & $47 \cdot 2$ & $93 \cdot 2$ & $37 \cdot 3$ & 0.448 & 0.32 & $-4 \cdot 47,5 \cdot 10$ & 0.41 & $-3 \cdot 91,4 \cdot 72$ \\
\hline Total fat $(\mathrm{g} / \mathrm{d}) \|$ & 235 & $77 \cdot 2$ & $38 \cdot 9$ & $71 \cdot 0$ & $37 \cdot 4$ & $0 \cdot 426$ & -0.43 & $-5 \cdot 04,4 \cdot 17$ & -0.24 & $-4 \cdot 45,3 \cdot 96$ \\
\hline PUFA $(g / d) \|$ & 235 & $19 \cdot 7$ & $9 \cdot 8$ & $19 \cdot 0$ & $10 \cdot 1$ & 0.403 & $0 \cdot 17$ & $-1 \cdot 16,1 \cdot 50$ & 0.22 & $-0 \cdot 92,1 \cdot 36$ \\
\hline MUFA $(g / d) \|$ & 235 & $27 \cdot 1$ & $15 \cdot 2$ & $24 \cdot 2$ & $14 \cdot 4$ & 0.074 & -1.39 & $-3 \cdot 26,0 \cdot 49$ & $-1 \cdot 30$ & $-2 \cdot 95,0 \cdot 36$ \\
\hline SFA $(g / d) \|$ & 235 & $22 \cdot 4$ & $13 \cdot 4$ & $20 \cdot 2$ & $12 \cdot 1$ & $<0.001$ & $-5 \cdot 34$ & $-5 \cdot 41,-5 \cdot 28$ & $-5 \cdot 34$ & $-5 \cdot 40,-5 \cdot 28$ \\
\hline Fibre (g/d)\| & 235 & $27 \cdot 3$ & $14 \cdot 2$ & $27 \cdot 3$ & $12 \cdot 9$ & $<0.001$ & $-1 \cdot 67$ & $-1 \cdot 73,-1 \cdot 61$ & $-1 \cdot 67$ & $-1 \cdot 73,-1 \cdot 62$ \\
\hline Alcohol $(g / d) \|$ & 235 & $5 \cdot 6$ & $13 \cdot 2$ & $4 \cdot 7$ & $10 \cdot 8$ & 0.390 & -0.07 & $-0.58,0.44$ & -0.07 & $-0.51,0.36$ \\
\hline Physical activity (min/week)§ & 240 & $49 \cdot 3$ & $51 \cdot 3$ & $49 \cdot 1$ & $50 \cdot 9$ & $0 \cdot 330$ & 0.09 & $-0.32,0.50$ & 0.09 & $-0.30,0.48$ \\
\hline Weekly frequency of physical activity & 240 & $4 \cdot 0$ & $3 \cdot 6$ & $4 \cdot 1$ & $3 \cdot 5$ & 0.045 & $0 \cdot 18$ & $-0.03,0.39$ & $0 \cdot 18$ & $-0 \cdot 02,0 \cdot 40$ \\
\hline
\end{tabular}

WC, waist circumference; DBP, diastolic blood pressure; SBP, systolic blood pressure; TC, total cholesterol; HDL-C, HDL cholesterol; LDL-C, LDL cholesterol. "Paired Student $t$ test.

tAbsolute change $=$ (final minus baseline value)

Adjusted to baseline value and number of examinations.

og-transformed value for statistical test.

Energy-adjusted value by the residual method for statistical test and confidence interval estimation. 
Table 2 Baseline and final mean values with standard deviations, and absolute change and adjusted change with $95 \%$ confidence intervals, of anthropometric, clinical, biochemical, dietary and physical activity variables of Japanese-Brazilian women during the intervention programme, Bauru, São Paulo, Brazil, 2007

\begin{tabular}{|c|c|c|c|c|c|c|c|c|c|c|}
\hline \multirow[b]{2}{*}{ Variable } & \multirow[b]{2}{*}{$N$} & \multicolumn{2}{|c|}{ Baseline } & \multicolumn{2}{|c|}{ Final } & \multirow[b]{2}{*}{$P$ value* } & \multirow[b]{2}{*}{ Absolute changet } & \multirow[b]{2}{*}{$95 \% \mathrm{Cl}$} & \multirow[b]{2}{*}{ Adjusted changeł } & \multirow[b]{2}{*}{$95 \% \mathrm{Cl}$} \\
\hline & & Mean & SD & Mean & SD & & & & & \\
\hline Weight (kg) & 297 & $56 \cdot 0$ & $9 \cdot 3$ & $55 \cdot 6$ & $9 \cdot 5$ & 0.006 & -0.40 & $-0.71,-0.09$ & -0.40 & $0.71,-0.09$ \\
\hline $\mathrm{BMI}\left(\mathrm{kg} / \mathrm{m}^{2}\right)$ & 265 & $24 \cdot 5$ & $4 \cdot 1$ & $24 \cdot 6$ & $4 \cdot 2$ & $0 \cdot 143$ & 0.08 & $-0.07,0.24$ & 0.09 & $-0.07,0.24$ \\
\hline WC $(\mathrm{cm})$ & 296 & $86 \cdot 8$ & $9 \cdot 7$ & $83 \cdot 7$ & $10 \cdot 2$ & $<0.001$ & $-3 \cdot 16$ & $-3 \cdot 78,-2 \cdot 53$ & $-3 \cdot 15$ & $-3 \cdot 76,-2 \cdot 54$ \\
\hline $\mathrm{DBP}(\mathrm{mmHg})$ & 302 & $79 \cdot 6$ & $11 \cdot 9$ & $75 \cdot 6$ & $10 \cdot 5$ & $<0.001$ & -3.98 & $-5.02,-2 \cdot 94$ & $-3 \cdot 89$ & $-4 \cdot 78,-3.00$ \\
\hline SBP $(\mathrm{mmHg})$ & 302 & $136 \cdot 1$ & $23 \cdot 2$ & $130 \cdot 1$ & $19 \cdot 6$ & $<0.001$ & $-6 \cdot 02$ & $-7 \cdot 98,-4 \cdot 06$ & -5.99 & $-7 \cdot 61,-4 \cdot 38$ \\
\hline Fasting glucose (mg/dl) & 321 & $105 \cdot 6$ & $30 \cdot 8$ & $101 \cdot 9$ & $23 \cdot 2$ & 0.004 & -3.73 & $-6 \cdot 45,-1 \cdot 01$ & $-3 \cdot 73$ & $-5 \cdot 75,-1 \cdot 71$ \\
\hline TC (mg/dl) & 321 & $218 \cdot 1$ & $49 \cdot 5$ & $191 \cdot 8$ & $36 \cdot 3$ & $<0.001$ & $-26 \cdot 29$ & $-31 \cdot 29,-21 \cdot 28$ & $-26 \cdot 29$ & $-29 \cdot 81,-22 \cdot 76$ \\
\hline HDL-C (mg/dl) & 315 & $56 \cdot 4$ & $12 \cdot 3$ & $52 \cdot 0$ & $12 \cdot 3$ & $<0.001$ & $-4 \cdot 45$ & $-5 \cdot 55,-3 \cdot 34$ & $-4 \cdot 45$ & $-5 \cdot 46,-3 \cdot 44$ \\
\hline LDL-C (mg/dl) & 298 & $129 \cdot 2$ & $37 \cdot 8$ & $110 \cdot 0$ & $31 \cdot 1$ & $<0.001$ & $-19 \cdot 17$ & $-23 \cdot 21,-15 \cdot 13$ & $-19 \cdot 35$ & $-22 \cdot 46,-16 \cdot 25$ \\
\hline TAG $(\mathrm{mg} / \mathrm{dl}) \S$ & 320 & $150 \cdot 4$ & $103 \cdot 4$ & $155 \cdot 4$ & $132 \cdot 8$ & $0 \cdot 415$ & $5 \cdot 00$ & $-7 \cdot 89,17 \cdot 89$ & $5 \cdot 00$ & $-7 \cdot 57,17 \cdot 57$ \\
\hline Energy $(\mathrm{kJ} / \mathrm{d})$ & 303 & $7006 \cdot 1$ & $2215 \cdot 4$ & $6969 \cdot 7$ & $2676 \cdot 9$ & $0 \cdot 408$ & $-36 \cdot 48$ & $-343 \cdot 09,270 \cdot 12$ & $-19 \cdot 16$ & $-297 \cdot 32,259 \cdot 03$ \\
\hline Carbohydrate $(g / d) \|$ & 303 & $226 \cdot 2$ & $73 \cdot 3$ & $230 \cdot 3$ & $100 \cdot 2$ & 0.005 & 0.05 & $0.01,0.09$ & 0.05 & $0.02,0.09$ \\
\hline Protein $(\mathrm{g} / \mathrm{d}) \|$ & 303 & $70 \cdot 0$ & $26 \cdot 0$ & $68 \cdot 8$ & $26 \cdot 1$ & $<0.001$ & $-7 \cdot 49$ & $-10 \cdot 28,-4 \cdot 70$ & $-7 \cdot 59$ & $-10 \cdot 10,-5 \cdot 08$ \\
\hline Total fat $(\mathrm{g} / \mathrm{d}) \|$ & 303 & $56 \cdot 8$ & $23 \cdot 9$ & $52 \cdot 9$ & $24 \cdot 4$ & $<0.001$ & $-8 \cdot 48$ & $-11 \cdot 00,-5 \cdot 96$ & $-8 \cdot 48$ & $-10 \cdot 78,-6 \cdot 20$ \\
\hline PUFA $(\mathrm{g} / \mathrm{d}) \|$ & 303 & $15 \cdot 1$ & $7 \cdot 1$ & $14 \cdot 2$ & $7 \cdot 0$ & $<0.001$ & $-2 \cdot 20$ & $-3 \cdot 01,-1 \cdot 39$ & -2.06 & $-2 \cdot 72,-1 \cdot 40$ \\
\hline MUFA $(\mathrm{g} / \mathrm{d}) \|$ & 303 & $19 \cdot 4$ & $8 \cdot 8$ & $17 \cdot 8$ & $9 \cdot 2$ & $<0.001$ & -3.96 & $-4.97,-2.96$ & $-4 \cdot 00$ & $-4 \cdot 88,-3 \cdot 11$ \\
\hline SFA $(g / d) \|$ & 303 & $16 \cdot 6$ & $8 \cdot 4$ & $15 \cdot 6$ & $8 \cdot 5$ & $<0.001$ & $-5 \cdot 46$ & $-5 \cdot 51,-5 \cdot 40$ & $-5 \cdot 46$ & $-5 \cdot 50,-5 \cdot 41$ \\
\hline Fibre $(g / d) \|$ & 303 & $19 \cdot 7$ & $8 \cdot 7$ & $20 \cdot 9$ & $11 \cdot 6$ & $<0.001$ & $-1 \cdot 73$ & $-1 \cdot 79,-1 \cdot 67$ & $-1 \cdot 72$ & $-1 \cdot 77,-1 \cdot 67$ \\
\hline Alcohol $(\mathrm{g} / \mathrm{d}) \|$ & 303 & 0.35 & $2 \cdot 19$ & $0 \cdot 41$ & $2 \cdot 12$ & 0.059 & 0.24 & $-0.06,0.53$ & 0.25 & $0.01,0.49$ \\
\hline Physical activity (min/week)§ & 318 & $56 \cdot 3$ & $71 \cdot 2$ & $57 \cdot 5$ & $71 \cdot 5$ & $0 \cdot 269$ & 0.09 & $-0.21,0.39$ & $0 \cdot 10$ & $-0 \cdot 19,0.39$ \\
\hline Weekly frequency of physical activity & 318 & $3 \cdot 7$ & $3 \cdot \overline{2}$ & $3 \cdot 7$ & $3 \cdot 2$ & 0.262 & 0.05 & $-0 \cdot 10,0 \cdot 21$ & 0.05 & $-0 \cdot 10,0 \cdot 20$ \\
\hline
\end{tabular}

WC, waist circumference; DBP, diastolic blood pressure; SBP, systolic blood pressure; TC, total cholesterol; HDL-C, HDL cholesterol; LDL-C, LDL cholesterol.

${ }^{*}$ Paired Student $t$ test.

tAbsolute change $=$ (final minus baseline value)

$\ddagger$ Adjusted to baseline value and number of examinations.

$\S$ Log-transformed value for statistical test.

Energy-adjusted value by the residual method for statistical test and confidence interval estimation 
Table 3 Mean absolute change with standard deviations ${ }^{*},+$ for anthropometric, clinical, biochemical, dietary and physical activity variables of Japanese-Brazilians during the intervention programme according to gender and achievement of the study goal, Bauru, São Paulo, Brazil, 2007

\begin{tabular}{|c|c|c|c|c|c|c|c|c|c|c|}
\hline \multirow[b]{3}{*}{ Variable } & \multicolumn{5}{|c|}{ Study goal achieved: yes } & \multicolumn{5}{|c|}{ Study goal achieved: no } \\
\hline & \multicolumn{2}{|c|}{$\operatorname{Men}(n 51)$} & \multicolumn{2}{|c|}{ Women ( $n$ 121) } & \multirow[b]{2}{*}{$P$ value $\ddagger$} & \multicolumn{2}{|c|}{ Men $(n$ 181) } & \multicolumn{2}{|c|}{ Women ( $n$ 176) } & \multirow[b]{2}{*}{$P$ value $\neq$} \\
\hline & Mean change & SD & Mean change & SD & & Mean change & SD & Mean change & SD & \\
\hline Weight (kg) & $-3 \cdot 36$ & $3 \cdot 17$ & $-1 \cdot 67$ & $2 \cdot 23$ & $<0.001$ & -0.24 & $2 \cdot 10$ & 0.47 & $2 \cdot 71$ & 0.003 \\
\hline BMI $\left(\mathrm{kg} / \mathrm{m}^{2}\right)$ & -0.93 & $1 \cdot 24$ & -0.57 & $1 \cdot 00$ & 0.025 & $0 \cdot 31$ & 0.91 & 0.58 & $1 \cdot 25$ & 0.015 \\
\hline WC $(\mathrm{cm})$ & $-9 \cdot 78$ & $13 \cdot 07$ & $-7 \cdot 97$ & $4 \cdot 31$ & 0.088 & $0 \cdot 17$ & $3 \cdot 19$ & 0.21 & $2 \cdot 83$ & $0 \cdot 456$ \\
\hline $\mathrm{DBP}(\mathrm{mmHg})$ & $-5 \cdot 65$ & $10 \cdot 03$ & $-4 \cdot 89$ & $9 \cdot 53$ & $0 \cdot 320$ & $-4 \cdot 06$ & $10 \cdot 02$ & $-3 \cdot 28$ & $8 \cdot 88$ & $0 \cdot 217$ \\
\hline $\mathrm{SBP}(\mathrm{mmHg})$ & $-12 \cdot 07$ & $19 \cdot 85$ & $-8 \cdot 38$ & $17 \cdot 52$ & $0 \cdot 113$ & $-5 \cdot 82$ & $15 \cdot 79$ & $-4 \cdot 60$ & $16 \cdot 98$ & $0 \cdot 241$ \\
\hline Fasting glucose (mg/dl) & $-9 \cdot 66$ & $29 \cdot 02$ & $-4 \cdot 31$ & $19 \cdot 13$ & 0.078 & $-6 \cdot 33$ & $22 \cdot 13$ & $-1 \cdot 87$ & $28 \cdot 09$ & 0.048 \\
\hline TC (mg/dl) & $-32 \cdot 81$ & $35 \cdot 34$ & $-28 \cdot 67$ & $37 \cdot 20$ & $0 \cdot 250$ & $-17 \cdot 51$ & $39 \cdot 50$ & $-23 \cdot 75$ & $52 \cdot 54$ & $0 \cdot 103$ \\
\hline HDL-C (mg/dl) & -0.43 & $11 \cdot 52$ & $-4 \cdot 70$ & $9 \cdot 04$ & 0.005 & $-3 \cdot 53$ & $10 \cdot 63$ & $-4 \cdot 16$ & $10 \cdot 70$ & 0.289 \\
\hline LDL-C (mg/dl) & $-19 \cdot 64$ & $31 \cdot 33$ & $-20 \cdot 19$ & 34.94 & $0 \cdot 465$ & $-13 \cdot 17$ & $35 \cdot 43$ & $-17 \cdot 50$ & $36 \cdot 12$ & $0 \cdot 137$ \\
\hline TAG $(\mathrm{mg} / \mathrm{dl}) \S$ & $-96 \cdot 55$ & $212 \cdot 73$ & $-12 \cdot 04$ & $96 \cdot 50$ & $<0.001$ & -3.92 & $199 \cdot 83$ & $17 \cdot 64$ & $134 \cdot 05$ & $0 \cdot 119$ \\
\hline Energy $(\mathrm{kJ} / \mathrm{d})$ & $-269 \cdot 24$ & $2656 \cdot 71$ & $-199 \cdot 37$ & $2033 \cdot 89$ & 0.428 & $-703 \cdot 08$ & $3325 \cdot 82$ & $53 \cdot 60$ & $2984 \cdot 57$ & $0 \cdot 013$ \\
\hline Carbohydrate $(g / d) \|$ & $0 \cdot 10$ & $0 \cdot 30$ & 0.01 & $0 \cdot 30$ & 0.051 & $0 \cdot 11$ & 0.29 & 0.06 & 0.34 & 0.085 \\
\hline Protein $(\mathrm{g} / \mathrm{d}) \|$ & $-1 \cdot 63$ & $32 \cdot 79$ & $-7 \cdot 17$ & $23 \cdot 40$ & $0 \cdot 113$ & 0.83 & $38 \cdot 11$ & $-7 \cdot 75$ & $23 \cdot 12$ & 0.006 \\
\hline Total fat $(\mathrm{g} / \mathrm{d}) \|$ & $-3 \cdot 73$ & $29 \cdot 59$ & $-10 \cdot 52$ & $21 \cdot 64$ & 0.053 & $-0 \cdot 36$ & $37 \cdot 63$ & $-7 \cdot 23$ & $22 \cdot 43$ & 0.021 \\
\hline PUFA (g/d)\| & $-2 \cdot 22$ & $6 \cdot 40$ & $-2 \cdot 84$ & $6 \cdot 97$ & $0 \cdot 300$ & 0.61 & $11 \cdot 19$ & $-1 \cdot 58$ & $6 \cdot 96$ & 0.016 \\
\hline MUFA $(g / d) \|$ & $-2 \cdot 69$ & $11 \cdot 93$ & $-4 \cdot 91$ & $8 \cdot 39$ & 0.089 & $-1 \cdot 23$ & $15 \cdot 48$ & $-3 \cdot 39$ & $9 \cdot 29$ & $0 \cdot 059$ \\
\hline SFA $(g / d) \|$ & $-5 \cdot 36$ & 0.50 & $-5 \cdot 50$ & 0.50 & 0.059 & $-5 \cdot 35$ & 0.54 & $-5 \cdot 44$ & 0.46 & 0.051 \\
\hline Fibre $(g / d) \|$ & $-1 \cdot 73$ & 0.41 & $-1 \cdot 81$ & 0.52 & $0 \cdot 188$ & $-1 \cdot 67$ & 0.48 & $-1 \cdot 67$ & 0.52 & 0.495 \\
\hline Alcohol (g/d)\| & $0 \cdot 27$ & 3.53 & $0 \cdot 41$ & $2 \cdot 65$ & $0 \cdot 389$ & $-0 \cdot 12$ & $3 \cdot 83$ & 0.04 & $2 \cdot 57$ & $0 \cdot 331$ \\
\hline Physical activity (min/week)§ & 0.02 & $2 \cdot 55$ & $-0 \cdot 10$ & 1.99 & $0 \cdot 369$ & $0 \cdot 12$ & $3 \cdot 49$ & $0 \cdot 24$ & $3 \cdot 26$ & $0 \cdot 365$ \\
\hline Weekly frequency of physical activity & 0.04 & $0 \cdot 60$ & -0.01 & 0.93 & $0 \cdot 367$ & 0.23 & $1 \cdot 87$ & $0 \cdot 10$ & $1 \cdot 73$ & $0 \cdot 246$ \\
\hline
\end{tabular}

WC, waist circumference; DBP, diastolic blood pressure; SBP, systolic blood pressure; TC, total cholesterol; HDL-C, HDL cholesterol; LDL-C, LDL cholesterol.

"Absolute change $=$ (final minus baseline value)

tAdjusted to baseline value and number of examinations.

$\ddagger$ Student's $t$ test.

$\$$ Log-transformed value for statistical test.

|Energy-adjusted value by the residual method for statistical test. 
was representative of all Japanese-Brazilians who agreed to participate in this nutritional intervention programme.

The absence of a control group did not allow us to show that the results of the study were actually due to the intervention programme. Randomized controlled intervention studies are more efficient to evaluate causal relationships. However, there are ethical or logistical situations in which this type of study is not advisable. One of the most frequent, which applies to the current study, is the ethical consideration. When the effectiveness of an intervention is well known and established, proven by previous studies, then the ethical question arises and does not allow the denial of treatment to a group of individuals ${ }^{(29)}$. As previously described $^{(7,8)}$, this Japanese-Brazilian community demonstrated a high prevalence of metabolic syndrome components and initiatives to minimize this problem were needed urgently. In this context, the JBDSG researchers conducted the present nutritional intervention study. It is important to note that the results found in the present study are in agreement with those previously published ${ }^{(9-14,21-23)}$. Also, the absolute change adjustment to baseline values and number of examinations may have contributed to reduce the possibility of bias in the present results.

Some limitations of the study must be taken into consideration. First, although it is known that the motivation to change dietary and health habits of the subjects who entered the intervention study may be different from that of non-participants (people who were invited but, for different reasons, did not want or could not join the programme), this fact does not jeopardize the results. Second, the supposition that all intervention programme subjects adhered to the treatment has not been evaluated; but it is presumed that if $100 \%$ of the subjects had adhered, the positive results would have been higher. Third, it is known that measurement mistakes in food intake and physical activity cannot be eliminated entirely, but the choice of a standardized methodology to collect information has probably minimized the risks. Fourth, the combined analysis of the data of subjects who were evaluated two or three times may have reduced the observed effects, as intervention benefits may be higher in shorter periods of time. Finally, the results refer to a 2-year follow-up of Japanese-Brazilian subjects but the longterm impact is unknown.

It can be concluded that the intervention programme was of benefit to those Japanese-Brazilian subjects who incorporated healthier lifestyle habits, as reflected in their nutritional and metabolic profile. Other studies are necessary to evaluate the effects of the benefits over longer periods of time.

\section{Acknowledgements}

Sources of funding: Fundação de Amparo a Pesquisa do Estado de São Paulo (FAPESP, 2005/59178-7) and Conselho Nacional de Desenvolvimento Científico e Tecnológico
(CNPq, 505845/2004-0). Conflict of interest: None declared. Contribution of each author: R.D. participated in planning and execution of the nutritional intervention study, in data collection and in manuscript writing. D.S.S., A.H., F.M., J.P., M.R.B., R.C. and V.L.M.A.d.S. participated in planning and execution of the nutritional intervention study, in data collection and in manuscript review. L.A. participated in the planning and writing of the manuscript. S.R.G.F. participated in planning and execution of the nutritional intervention study, in data collection, in manuscript review and in funding obtaining to support the research (CNPq, 505845/ 2004-0). S.A. participated in the planning, statistical analysis and writing of the manuscript. S.G.A.G. participated in planning and execution of the nutritional intervention study, in data collection, in manuscript writing and in obtaining funding to support the research (FAPESP, 2005/59178-7). Acknowledgements: The authors thank the Japanese-Brazilian community living in Bauru for their kind cooperation.

\section{References}

1. World Health Organization \& Food and Agricultural Organization of the United Nations (2003) The Scientific Basis for Diet, Nutrition and the Prevention of Type 2 Diabetes. Geneva: WHO.

2. Esmaillzadeh A \& Azadbakht L (2008) Major dietary patterns in relation to general obesity and central adiposity among Iranian women. J Nutr 138, 358-363.

3. Fujimoto WY, Bergstrom RW, Boyko EJ et al. (2000) Type 2 diabetes and the metabolic syndrome in Japanese Americans. Diabetes Res Clin Pract 50, 73-76.

4. Centro de Estudos Nipo-Brasileiros (1990) Pesquisa da população de descendentes de japoneses residentes no Brasil: 1987-1988 (Population Research of Japanese People and Their Descendents Living in Brazil: 1987-1988). São Paulo: Japanese-Brazilian Study Center.

5. Fujimoto WY, Bergstrom RW, Boyko EJ et al. (1994) Diabetes and diabetes risk factors in second and thirdgeneration Japanese-Americans in Seattle, Washington. Diabetes Res Clin Pract 24, 43-52.

6. Alberti KGMM \& Zimmet PZ, for the WHO Consultation (1999) Definition, diagnosis and classification of diabetes mellitus and its complications. Part 1: Diagnosis and classification of diabetes mellitus. Report of a WHO Consultation. Diabet Med 15, 539-553.

7. Gimeno SGA, Ferreira SRG, Franco LJ et al.; JBDSG (2002) Prevalence and 7-year incidence of type 2 diabetes mellitus in a Japanese-Brazilian population: an alarming public health problem. Diabetologia 45, 1635-1638.

8. Rosenbaum P, Gimeno SGA, Sanudo A et al. (2005) Analysis of criteria for metabolic syndrome in a population-based study. Diabetes Obes Metab 7, 352-359.

9. Pan XR, Li GW, Hu YH et al. (1997) Effects of diet and exercise in preventing NIDDM in people with impaired glucose tolerance: The Da Qing IGT and Diabetes Study. Diabetes Care 20, 537-544.

10. Tuomilehto J, Lindstrom J, Eriksson JG et al. (2001) Prevention of type 2 diabetes mellitus by changes in lifestyle among subjects with impaired glucose tolerance. $N$ Engl J Med 344, 1343-1350.

11. Knowler WC, Barrett-Conner E, Fowler SE et al. (2002) Diabetes Prevention Program Research Group. Reduction in the incidence of type 2 diabetes with lifestyle intervention or metformin. N Engl J Med 346, 393-403. 
12. Sarrafzadegan N, Kelishadi R, Esmaillzadeh A et al. (2009) Do lifestyle interventions work in developing countries? Findings from the Isfahan Healthy Heart Program in the Islamic Republic of Iran. Bull World Health Organ 87, 39-50.

13. Sartorelli DS, Sciarra EC, Franco LJ et al. (2004) Primary prevention of type 2 diabetes through nutritional counseling. Diabetes Care 27, 3019.

14. Sartorelli DS, Sciarra EC, Franco LJ et al. (2005) Beneficial effects of short-term nutritional counselling at the primary health care level among Brazilian overweight adults. Public Health Nutr 8, 820-825.

15. NEPA/UNICAMP (2006) Tabela Brasileira de Composição de Alimentos (Brazilian Table of Food Composition). Campinas, São Paulo: NEPA/UNICAMP.

16. Tomita LY \& Cardoso MA (2002) Relação de Medidas Caseiras, Composição Química e Receitas de Alimentos Nipo-Brasileiros (Housebold Measures, Food Composition and Japanese-Brazilians Food Preparations). São Paulo: Editora Metha.

17. Resources Council, Science and Technology Agency (1993) Standard Tables of Food Composition in Japan, 4th ed. Tokyo: Women's University of Nutrition Press.

18. Matsudo S, Timoteo A, Matsudo V et al. (2001) Questionário Internacional de Atividade Física (IPAQ): estudo de validade e reprodutibilidade no Brasil (International Physical Activity Questionnaire (IPAQ): validity and reproducibility study in Brazil). Rev Bras Ativ Fis Saude 6, 5-18.

19. Craig CL, Marshall AL, Sjostrom M et al. (2003) International Physical Activity Questionnaire - IPAQ: 12-country reliability and validity. Med Sci Sports Exerc 35, 1381-1395.

20. Willett WC \& Stampfer MJ (1986) Total energy intake: implications for epidemiological analysis. Am J Epidemiol 124, 17-27.

21. Forti N \& Diament J (1996) Dislipidemia e prevenção primária da doença coronária ateroscleróstica (Dyslipidemia and atherosclerotic coronary disease prevention). Rev Soc Cardiol 5, 620-626.

22. Eberly LE, Neaton JD, Thomas AJ et al. (2004) Multiple risk factor intervention trial research group. Multiple-stage screening and mortality in the Multiple Risk Factor Intervention Trial. Clin Trial 2, 148-161.

23. Siedel MC, Powell RO, Zgibor JC et al. (2008) Translating the Diabetes Prevention Program into urban medically underserved community: a nonrandomized prospective intervention study. Diabetes Care 31, 684-689.
24. Tucker KL (2007) Assessment of usual dietary intake in population studies of gene-diet interaction. Nutr Metab Cardiovasc Dis 17, 74-81.

25. Bo S, Ciccone G, Baldi C et al. (2007) Effectiveness of a lifestyle intervention on metabolic syndrome: a randomized controlled trial. J Gen Intern Med 22, 1695-1703.

26. Davis-Smith YM, Boltri JM, Seale JP et al. (2007) Implementing a diabetes prevention program in a rural African-American church. I Natl Med Assoc 99, 440-446.

27. Mayer-Davis EJ, D'Antonio AM, Smith SM et al. (2004) Pounds Off With Empowerment (POWER): a clinical trial of weight management strategies for black and white adults with diabetes who live in medically underserved rural communities. Am J Public Health 94, 1736-1742.

28. Pagoto SL, Kantor L, Bodenlos JS et al. (2008) Translating the diabetes prevention program into a hospital-based weight loss program. Health Psychol 27, 1 Suppl., S91-S98.

29. Harris AD, McGregor JC, Perencevich EN et al. (2006) The use and interpretation of quasi-experimental studies in medical informatics. I Am Med Inform Assoc 13, 16-23.

\section{Appendix}

\section{Members of Japanese-Brazilian Diabetes Study Group}

A. Hirai, A.T. Hirai, H. Harima, M. Kikuchi, K. Osiro, S.G.A. Gimeno (Department of Preventive Medicine, Federal University of São Paulo, Brazil); R. Damião (Nutrition Graduation Course of Triângulo Mineiro Federal University, Brazil); L.J. Franco, D. Sartorelli (Department of Social Medicine, Faculty of Medicine of Ribeirão Preto, University of São Paulo, Brazil); L. Matsumura (Department of Internal Medicine, Federal University of São Paulo, Brazil); K. Wakisaka (Japanese-Brazilians Study Center, Brazil); R. Chaim (Department of Nutrition, University of Sagrado Coração de Jesus, Bauru, Brazil); M.A. Cardoso, S.R.G. Ferreira (Department of Nutrition, School of Public Health, University of São Paulo, Brazil). 